\title{
Analisis Pengaruh Modal Manusia (Human Capital) Terhadap Kinerja Koperasi Di Kota Pekanbaru
}

\author{
Fakhri Rabialdy \\ Universitas Pahlawan \\ e-mail : Fakhrirabialdy@gmail.com
}

\begin{abstract}
Abstrak
Penelitian ini bertujan untuk menguji hubungan modal manusia (human capital) terhadap kinerja koperasi di kota Pekanbaru. Peneliti menggunakan penelitian kuantitif dengan kuesioner sebagai alat ukur penelitian. Modal manusia (human capital) terdiri dari tiga dimensi yaitu kompetensi pengurus, pengalaman kerja pengurus dan pendidikan pengurus. 118 kuesioner telah di sebarkan kepada pengurus koperasi melalui metode tatap muka dan daring (dalam jaringan). Namun, hanya 100 kuesioner atau $84.7 \%$ response rate yang digunakan untuk analisis selanjutnya. Semua data di analisis menggunakan SPSS versi 24. Hasil penelitian ini menemukan bahwa kompetensi pengurus memiliki hubungan yang signifikan terhadap kinerja koperasi. Maka, semakin tinggi kompetensi pengurus maka semakin tinggi kinerja koperasi di Kota Pekanbaru.
\end{abstract}

Kata Kunci:sumber daya manusia, kinerja organisasi, kompetensi karyawan, pengalaman kerja karyawan dan pendidikan karyawan

\begin{abstract}
This research aimed to examine the relationship between human capital and cooperative performance in Pekanbaru city. The researcher used quantitative approach with questionnaire as an instrument of this study. Human capital consists of three dimensions, employee competency, employee working experience and employee education. 118 questionaries were distributed to the cooperative's board through direct and online method. However, only 100 questionnaires or $84.7 \%$ response rate used for further analysis. All data were analyzed by using SPSS version 24. The finding of this study indicated employee competence has a positive and significant relationship to the cooperative performance. Thus, high competency of employee will effect to the high performance of cooperative in Pekanbaru City.
\end{abstract}

Keywords:human capital, organizational performance, employee competency, employee working experience and employee education.

\section{PENDAHULUAN}

Kinerja dapat disimpulkan sebagai kegiatan yang berhubungan dengan pekerjaan atau sebagai hasil pencapain dari pekerjaan dikarenakan kinerja memiliki hubungan dengan tujuan strategiorganisasi, kepuasan pelanggan dan kontribusi ekonomi (Salem, 2003).Dikutip dari Hamid, dkk (2017)bahwa kinerja dianggap penting bagi setiap organisasi, bahkan dijadikan sebagai tujuan agar meningkatkan kinerja dalam mencapai tujuan organisasi. Pada dasarnya, kinerja organisasi melibatkan aktivitas yang dilakukan berulang-ulang dalam menetapkan tujuan organisasi, memantau kemajuan dan membuat penyesuaian untuk mencapai tujuan secara efektif dan efisien(Ratna, dkk., 2014).

Selain dari pada itu, kinerja organisasi memiliki peran penting dalam perekonomian sebuah negara. Seperti contoh,koperasi sebagai suku ekonomi negara dituntut untuk membantu mewujudkan kesejahteraan dan kemakmuran rakyat(Hanny, dkk., 2017).Namun, pada nyatanya, koperasidi Indonesia belum mampu mewujudkan apa yang telah tertulis dalam Undang - Undang no 25 tahun 1992 terkait tujuan dari koperasi. 
Selain itu, dikutip dalam penelitian Agusalim dkk., (2018)bahwa koperasi menempati peringkat kelima dengan kontribusi kurang dari 5\% sedangkan perusahaan swasta memiliki kontribusi terbesar pada Produk Domestik Bruto Indonesia dan dikuti oleh BUMN (badan usaha milik negara). Bahkan, koperasi di kota Pekanbaru mengalami masalah yang ditunjukan dengan 302 koperasiakan dibekukan(Gilangnews, 2017). Siregar(2019)menambahkan bahwa 313 koperasi akan di tutup oleh Pemerintah Kota Pekanbaru. Dengan demikian, dapat disimpulkan bahwa kinerja koperasi di kota Pekanbaru memiliki hambatan.

Penelitian terdahulu menunjukan terdapat dua faktor yang mempengaruhi kinerja organisasi yaitu internal dan eksternal faktor(Kareem \& Haseeni, 2015). Menurut mereka, internal factor dapat didefenisikan sebagai faktor - faktor yang di kontrol oleh organisasi, sedangkan eskternal factor adalah faktor yang tidak dikontrol oleh organisasi. Selain itu, Barney(1991)menambahkan bahwa resource-based theory yang mana menguji hubunganan tarasumber daya perusahaan dengan keunggulan kompetitif. Dalam penelitian tersebut, terdapat tiga sumber daya yang berada di organisasi yaitu modal fisik(physical capital), modal manusia(human capital), dan modal organisasi (organizational capital). Modal fisik (physical capital) meliputi teknologi, alatalat yang digunakan oleh organisasi, dan lainnya. Modal organisasi (organizational capital)meliputi organisasis truktural, hubungan kepada pihak luar dan lainnya. Sedangkan modal manusia (human capital) meliputi pelatihan, pengalaman kerja, kemampuan dan lainnya yang dimiliki oleh manusia.

Beberapa penelitian terdahulu menunjukan bahwa modal manusia memiliki peran penting dalam sebuah organisasi(eg. Anggraini dkk., 2018; Azzahra, 2018; Saengchai \& Sutduean, 2019). Penelitian tersebut didukung oleh Mufti dkk., (2016)bahwa resource-based theory(RBT) menunjukan sumber daya manusia dapat berkontribusi kepada keunggulan kompetitif dengan memanfaatkan pengembangan kompetensi pada organisisasi, menghasilkan hubungan social yang kompleks, mencerminkan sejarah dan budaya perusahaan. Ali dan Chaudhry(2017)menambahkan modal manusia(human capital)juga sebagai sumber keunggulan kompetitif terbesar bagi organisasi yang tidak dapat dengan mudah ditiru oleh organisasi lain sementara modal lain seperti modal structural atau keuangan dapat disalin dengan mudah.Beberapa penelitian terdahulu mengemukakan modal manusia(human capital)sebagai kombinasi dari pengetahuan, kompetensi, innovasi dan kemampuan pada diri seseorang yang bertujuan untuk membentuk dan mencapai sebuah tujuan(Bontis, 2001; Ongkorahardjo, dkk., 2008). Selain itu, modal manusia(human capital)juga didefenisikan sebagai kombinasi dari skill, dan kemampuan seseorang bekerja di organisasi(Ramli, dkk., 2014; Wang, dkk., 2008).

Berdasarkan uraian diatas, penelitian ini bertujuan untuk menganalisis hubungan modal manusia(human capital)terhadap kinerja Koperasi di Kota Pekanbaru. Pada penelitian ini, modal manusia (human capital) terdiri dari kompetensi, pengetahuan dan pengalaman kerja pada pekerja(Ramli, dkk., 2014; Wang, dkk., 2008). Sedangkan kinerja organisasi diukur dari peningkatan keuntungan, peningkatan penjualan, dan kinerja keseluruhan organisasi(Khan, dkk., 2016).

\section{METODE}

Peneliti menggunakan metode kuantitatif untuk menganalisis hubungan modal manusia(human capital)terhadap kinerja Koperasi di Kota Pekanbaru. Dalam penelitian ini, metode kuantitatif bertujuan untuk menjelaskan fenomena dari data yang dianalisisdengan metode matematika, seperti statistik(Yilmaz, 2013).Metode kuantitif juga sebagai metode pengumpulan data yang effisien ketika peneliti tau apa yang dibutuhkan dan bagaimana mengukur variabel yang diminati(Sekaran, 2003). Selanjutnya,kota Pekanbaru memiliki 178 koperasi aktif bahkan telah meneyelenggarakan RAT (rapat akhir tahun). Jumlah kopeasi tersebut digunakan sebagai populasi dalam penelitian ini. Dalam menentukan jumlah sampel, peneliti merujuk kepada penelitian dari Krejcie dan Morgan(1970)yang menunjukan bahwa jika jumlah populasi ialah diantara 170 hingga 179 maka jumlah sampel yang dibutuhkanialah 118 koperasi. 
Selain itu, penelitian ini menggunakan alat ukur kuesioner dalam proses pengumpulan data. Dikutip dari buku yang ditulis Ranjit Kumar(2011), kuesioner ialah daftar pertanyaan tertulis yang digunakan untuk mereka menjawab pandariresponden. Selanjutnya, kuesionar disebarkan menggunakan simple random sampling dikarenakan metode ini mampu memberikan peluang dan kesempatan yang sama bagi responden dalam memberikan informasi yang benar. Setelah data terkumpul, peneliti menganalisis data dengan menggunakan uji korelasi dan uji regresi untuk menjawab pertanyaan pertanyaan dalam penelitian ini.

\section{HASIL DAN PEMBAHASAN}

\subsection{Hasil Penelitian}

\subsubsection{Analisis Deskiptif}

Pada penelitianini, peneliti menggunakan 84.7\% reponse rate atau 100 kuesioner yang telah diisi oleh reponden. Berdasarkan data yang diterima, bahwa tahun pembentukan koperasi terbagi menjadi 5 kategori seperti yang tertera di table 1. Selain itu, penelitian ini juga menunjukan bahwa rata rata latar belakang pendidikan pengurus koperasi ialah sekolah menegah pertama, sekolah menengah atas, sarjana strata satu, sarjana strata duaseperti yang ditujukan pada table 1.

Table 1

Tahun Bedirinya Koperasi

\begin{tabular}{lll}
\hline Item & Frekuensi & Persen $(\%)$ \\
\hline$<1980$ & 4 & 4 \\
\hline $1981-1990$ & 17 & 17 \\
\hline $1991-2000$ & 23 & 23 \\
\hline $2001-2010$ & 41 & 41 \\
\hline$>2011$ & 15 & 15 \\
\hline
\end{tabular}

Berdasarkan tabel 1, koperasi yang berada di kota Pekanbaru terbagi atas 5 kategori berdasarkan tahun pembentukan yaitu koperasi yang bediri sebelum tahun 1980 terdapat 4 unit. Koperasi yang berdiri pada tahun 1981 hingga 1990 sebanyak 17 unit. 23 unit koperasi yang bediri pada tahun 1991 hingga 2000. Koperasi yang bediri pada 2001 hingga 2010 sebanyak 41 unit. Dan terakhir koperasi yang bediri diatas tahun 2011 sebanyak 15 unit.

Table 2

Rata- Rata Latar Belakang Pendidikan Pengurus

\begin{tabular}{ccc}
\hline Item & Frekuensi & Persen (\%) \\
\hline $\begin{array}{c}\text { SekolahMenengahPertama } \\
\text { (SMP) }\end{array}$ & 2 & 2 \\
\hline $\begin{array}{c}\text { SekolahMenengahAtas } \\
\text { (SMA) }\end{array}$ & 32 & 32 \\
\hline Sarjana strata satu (S1) & 57 & 57 \\
\hline Sarjana strata dua (S2) & 9 & 9 \\
\hline
\end{tabular}


Tabel 2 menunjukan bahwa rata rata pengurus koperasi yang berada di kota Pekanbaru terdiri atas 4 kategori yang dibedakan menurut jenjang pendidikan. Sarjana strata satu sebagai jenjang pendidikan terbanyak yang dimiliki oleh 57 unitkoperasi, diikuti oleh pengurus koperasi yang berlatar belakang SMA sebanyak 32 unit koperasi dan sarjana strata dua sebanyak 9 unit koperasi. Koperasi di kota Pekanbaru memiliki 2 unit koperasi yang masih memiliki pengurus berlatar belakang SMP.

\subsubsection{Analisis Korelasi}

Penelitian ini juga menggunakan uji korelasi untuk mengetahui hubungan antara modal manusia(human capital)sebagai independent variable terhadap Kinerja koperasi sebagai dependent variabel.Tabel 3 menunjukan bahwa dimensi modal manusia memiliki korelasi terhadap kinerja koperasi di Kota Pekanbaru yang ditunjukan bahwa coefficient correlation berada diantara 0.345 hingga 0.40. Menurut Piaw(Piaw, 2013), koefisient diantara 0.31 hingga 0.5 termasuk dalam kategori lemah. Dengan demikian dapat disimpulkan bawha dimensi modal manusia memiliki hubungan yang lemah terhadap kinerja koperasi di Kota Pekanbaru.

Table 1.

Pearson Correlation Coefficient

\begin{tabular}{ccccc}
\hline Construct & EE & EC & EWE & OP \\
\hline EE & 1 & & & \\
\hline EC & $0.566^{* *}$ & 1 & & \\
\hline EWE & $0.551^{* *}$ & $0.725^{* *}$ & 1 & 1 \\
\hline OP & $0.392^{* *}$ & $0.481^{* *}$ & $0.345^{* *}$ & \\
\hline
\end{tabular}

***Correlation is significant at level 0.01

\section{Analisis Regresi Berganda}

Hubungan modal manusia(human capital) dan kinerja koperasi pada penelitian ini dianalisis menggunakan analisis regresi berganda. Menurut Piaw(Piaw, 2013), regresi berganda digunakan untuk mengindentifikasi perubahan pada dua atau lebih faktor (independent variabel) terhadap dependenvariabel.Berdasarkan, tabel 4 bahwa tiga dari dimensi modal manusia hanya satu yang ditemukan memiliki hubungan yang signifikan. Pengalaman kerja pekerja (sig=0.090) dan pendidikan pekerja (0.640) ditemukan tidak memiliki hubungan yang signifikan kepada kinerja koperasi. Kompetensi pengurus memiliki hubungan yang signifikan terhadap kinerja koperasi di kota Pekanbaru $(\operatorname{sig}=0.002)$. 
Table 2.

Analisis Regresi Berganda

\begin{tabular}{ccc}
\hline Construct & Beta $(\boldsymbol{\beta})$ & Sig level \\
\hline EE & 0.189 & 0.090 \\
\hline EC & 0.419 & 0.002 \\
\hline EWE & -0.62 & 0.640 \\
\hline$* * \mathrm{P}<0.01, \mathrm{R}^{2}=0.254, \mathrm{~F}=10.879$ & \\
\hline
\end{tabular}

\subsection{PEMBAHASAN}

Berdasarkan uraian diatas, ditemukan bahwa kinerja koperasi dikota Pekanbaru dipengaruhi oleh kompetensi pengurus/pekerja. Penelitian ini mendukung penemuan yang dihasilkan oleh Osei dan Ackah (2015). Dalam penelitian tersebut, ditemukan bahwa kompetensi pekerja memiliki hubungan signifikan terhadap kinerja organisasi di perusahaan farmasi. Selain itu, kompetenesi pekerja ditemukan juga memiliki hubungan yang kuat terhadap kinerja organisasi di agen travel (Elbaz et al., 2018).

Selain itu, pengalaman pekerja dan pendidikan pekerja pada penelitian ini tidak memiliki hubungan yang signifikan terhadap kinerja koperasi di Kota Pekanbaru. Penelitian ini tidak sejalan dengan penelitian yang dilakukan oleh Urban dan Kongo (2015) bahwa pengalaman kerja dan pendidikan pekerja memiliki hubungan yang signikan terhadap kinerja organisasi di Industri retail di Kinshasa, Republik Demokratik Kongo.

\section{KESIMPULAN}

Temuan pada penelitian ini menemukan bahwa modal manusia memiliki hubungan terhadap kinerja koperasi di Kota Pekanbaru. Penelitian ini berhasil menemukan bahwa kompetensi pengurus memainkan peran penting dalam kinerja koperasi. Kompentensi pengurus memiliki hubungan yang signifikan terhadap kinerja koperasi di Kota Pekanbaru. Dengan demikian dapat disimpulkan jika semakin tinggi kompetensi yang dimiliki oleh pengurus, maka semakin tinggi pula kinerja yang ditunjukan oleh koperasi. Namun, jika semakin rendah kompetensi yang dimiliki maka rendah pula kinerja yang dihasilkan.

Selain itu, penelitian ini juga menemukan bahwa pendidikan pengurus dan pengalaman kerja pengurus tidak berperan penting dalam kinerja koperasi di Kota Pekanbaru. Dikarenakan, pendidikan pengurus dan pengalaman kerja pengurus tidak memiliki hubungan yang signifikan terhadap kinerja koperasi di Kota Pekanbaru. 


\section{SARAN}

Penelitian ini memiliki beberapa keterbatasan dalam melaksanakan penelitian seperti:

1. Penelitian ini menggunakan jumla sampel yang sedikit karena peneliti menggunakan koperasi aktif dan telah melaksanakan RAT, peneliti menyarankan agar penelitian selanjutnya yang berkaitan dengan koperasi dilakukan pada populasi dan sampel yang lebih besar.

2. Penelitian ini hanya menguji hubungan modal manusia (human capital), peneliti menyarankan agar penelitian selanjutnya mampu menambahkan variable atau faktor yang baru pada penelitian ini seperti orientasi kewirausahaan, dukungan pemerintah, dan lainnya.

3. Penelitian ini menyarankan agar pemerintah mampu member perhatian lebih terhadap koperasi dikarenakan koperasi sebagai suku ekonomi Indonesia agar mereka dapat berkontribusi lebih besar terhadap perekenomian Indonesia. 


\section{DAFTAR PUSTAKA}

[1] Agusalim, L., Karim, M., \& Yaddarabullah. (2018). Analisis perkembangan, kinerja, dan daya saing koperasi indonesia dalam pembangunan ekonomi. Memperkuat Produktivitas Pereknonomian Indonesia: Harmonisasi Sektor Formal Dan Informal, 71-83.

[2] Ali, H., \& Chaudhry, I. S. (2017). Effect of human capital on organization performance : an analysis from service sector of Punjab, Pakistan. European Online Journal of Natural and Social Sciences, $6(3), 475-481$.

[3] Anggraini, F., Abdul-Hamid, M. A., \& Azlina, M. K. A. (2018). The role of intellectual capital on public universities performance in Indonesia. Pertanika Journal of Social Sciences and Humanities, 26(4), 2453-2472.

[4] Azzahra, K. (2018). The influence of human capital, structural capital and relational capital to the performance of cooperation with competitive advantage as intervening. Economics and Accounting Journal, 1(1), 24-34.

[5] Barney, J. (1991). Firm Resources and Sustained Competitive Advantage. Journal of Management, 17(1), 99-120. https://doi.org/10.1177/014920639101700108

[6] Bontis, N. (2001). Assessing knowledge assets: a review of the models used to measure intellectual capital. International Journal of Management Reviews, 3(1), 41-60. https://doi.org/10.1111/14682370.00053

[7] Elbaz, A. M., Haddoud, M. Y., \& Shehawy, Y. M. (2018). Nepotism, employees' competencies and firm performance in the tourism sector: A dual multivariate and Qualitative Comparative Analysis approach. Tourism Management, 67, 3-16. https://doi.org/10.1016/j.tourman.2018.01.002

[8] Gilangnews. (2017). Koperasi di Pekanbaru Akan Dibekukan. Gilangnews.Com. https://gilangnews.com/news/detail/3928/koperasi-di-pekanbaru-akan-dibekukan

[9] Hamid, M., Maheen, S., Cheem, A., \& Yaseen, R. (2017). Impact of Human Resource Management on Organizational Performance. Journal of Accounting \& Marketing, 06(01), 1-7. https://doi.org/10.4172/2168-9601.1000213

[10] Hanny, Kurniawati, K., Waruwu, B. S. F., \& Pribadi, R. (2017). Analisis Reidentifikasi Empat Masalah Utama Koperasi di Kabupaten Subang sebagai Dasar Penyusunan Strategi. Jurnal Akuntansi Maranatha, 9(1), 54-73. https://doi.org/10.28932/jam.v9i1.491

[11] Kareem, M. A., \& Haseeni, Z. J. (2015). E-Government and Its Impact on Organizational Performance. International Journal of Management and Commerce Innovations, 3(1), 664-672.

[12] Khan, H. H. A., Abdullah, M. 'Aini Y. H., \& Ah, S. H. A. B. (2016). Factors affecting performance of co-operatives in Malaysia. International Journal of Productivity and Performance Management, 65(5), 641-671. https://doi.org/http://dx.doi.org/10.1108/IJPPM-05-2014-0077 
[13] KREJCIE, R. V., \& MORGAN, D. W. (1970). DETERMINING SAMPLE SIZE FOR RESEARCH ACTIVITIES. 30, 607-610. https://doi.org/10.1177/0013164405285548

[14] Mufti, O., Parvaiz, G. S., Wahab, M., \& Durrani, M. (2016). Human resource competencies and organizational performance: A study on banking sector managers in Pakistan. Journal of Managerial Sciences, $X(1), 83-104$.

[15] Ongkorahardjo, M. D. P. A., Susanto, A., \& Rachmawati, D. (2008). Analisis Pengaruh Human Capital Terhadap Kinerja Perusahaan (Studi Empiris pada Kantor Akuntan Publik di Indonesia). Jurnal Akuntansi Dan Keuangan, 10(1), 11-21. https://doi.org/10.9744/jak.10.1.PP. 11-21

[16] Osei, A. J., \& Ackah, O. (2015). Employee's Competency and Organizational Performance in The Pharmaceutical Industry. International Journal of Economics, Commerce and Management, III(3), $1-9$.

[17] Piaw, C. Y. (2013). Mastering Reseacrh Statistic. Mc Graw - Hill Education.

[18]Rajnish Ratna, Khanna, K., Jogishwar, N., Khattar, R., \& Agarwal, R. (2014). Impact of Learning Organization on Organizational Performance in Consulting Industry. International Journal on Global Business Management and Research ISSN International Journal on Global Business Management and Research, 2(2).

[19] Ramli, A., Poespowidjojo, D. A. L., \& Shakir, K. A. (2014). Modal Manusia dan Kaitannya dengan Kinerja : Suatu Kajian Terhadap Gudang Manufaktur Berlisensi di Semenanjung. 3(September).

[20] Ranjit Kumar. (2011). Research Methodology : A Step-by-step guide for beginers.

[21] Saengchai, S., \& Sutduean, J. (2019). The impact of intellectual capital on performance of Universities in Thailand: The mediating role of entrepreneur orientation. International Journal of Innovation, Creativity and Change, 6(10), 381-401.

[22] Salem, H. (2003). Organizational Performance Management and Measurement: The Lebanese Experience. Economic and Social Council for Western Asia.

[23]Sekaran, U. (2003). Research Methods For Business: A skill Building Approach. John Wiley \& Sons Inc.

[24] Siregar, T. (2019). 316 Koperasi di Pekanbaru Dibubarkan. Radio Republik Indonesia. http://rri.co.id/pekanbaru/post/berita/634744/ekonomi/316_koperasi_di_pekanbaru_dibubarkan.html

[25] Urban, B., \& Kongo, M. (2015). The relevance of human capital to firm performance: A focus on the retail industry in Kinshasa, Democratic Republic of Congo. Acta Commercii, 15(1), 1-9. https://doi.org/10.4102/ac.v15i1.261

[26] Wang, I.-M., Shieh, C., \& Wang, F.-J. (2008). Effect of Human Capital Investment on Organizational Performance. Social Behavior and Personality: An International Journal, 36(8), 1011-1022. https://doi.org/10.2224/sbp.2008.36.8.1011 